\title{
Influence of Photoperiod and Culture Medium on the Speed of Asymbiotic Seed Germination and Seedling Development in Spathoglottis plicata
}

\author{
Boris Andrés Bran Barrientos and Jong-Yi Fang ${ }^{1}$ \\ Department of Tropical Agriculture and International Cooperation, National \\ Pingtung University of Science and Technology, No. 1 Shueh Fu Road, \\ Neipu, Pingtung 91201, Taiwan
}

Additional index words. in vitro seed germination, garden orchid, seedling development stage, tissue culture protocol

\begin{abstract}
Spathoglottis plicata is an attractive, easy-to-grow, and floriferous terrestrial orchid that has become the most important horticulturally cultivated Spathoglottis species in Southeast Asia. The present research was conducted to study the asymbiotic seed germination and seedling development of this orchid under the influence of various photoperiod and medium treatments. Seeds from 28-day-old capsule were sown on five culture media, including half-strength Murashige and Skoog medium (1/2 MS), Orchid Seed Sowing Medium (OSSM), BM-1 Terrestrial Orchid Medium (BM-1), Vacin and Went Modified Orchid Medium (VW), and Knudson C Orchid Medium (KC), and incubated under 0/24-hour or 16/8-hour light/dark photoperiod. Seed germination occurred in all photoperiods and media tested but at different paces. Seeds subjected to total darkness germinated more rapidly in the first 3 weeks than those subjected to light. However, seed germination under light overtook or even exceeded seed germination under dark starting on the fourth week of culture. Seedlings grown on the OSSM and VW media showed the fastest development as they reached the advanced stage (Stage 6) within 11 weeks of culture. Seedlings on the BM-1 medium were the slowest to evolve, as they required more than 16 weeks' time to complete all the developmental stages. Lightincubated advanced stage seedlings were subcultured on the same medium until leaves and roots were well developed and acclimatized in the greenhouse with $100 \%$ survival.
\end{abstract}

With the increased popularity of orchids, a need exists for the introduction of new commercially valuable species to uphold consumer's attention. In recent years, commercial production and cultivation of native orchid species have increased considerably. The genus Spathoglottis includes about 50 species distributed in Southeast Asia and the Pacific region. All members of the genus Spathoglottis are terrestrial and most grow at low moderate altitudes (Beltrame, 2006). Many species have attractive purple, pink, white, and yellow medium- to large-sized flowers, which make them worthy subjects for cultivation. The most widely cultivated species of the genus is Spathoglottis plicata, commonly known as the garden orchid or ground orchid. Due to its hardiness and fast growth, it often is used in hybridizing with other mountain Spathoglottis that are difficult to grown in lowland to produce more interesting varieties. In Taiwan, native S. plicata is found in forest margins and grassy lowlands or slopes (Chen and Bell, 2009) or cultivated in gardens. Unlike most of the orchids, which require cooler environment to thrive, a mature $S$. plicata plant can tolerate the high summer temperatures and

Received for publication 15 May 2019. Accepted for publication 17 June 2019.

${ }^{1}$ Corresponding author. E-mail: jyfang@mail.npust. edu.tw. continues to bloom throughout the year in the central and southern part of the country. It has become a valuable ornamental plant in the market with great future potential.

$S$. plicata is conventionally propagated by the separation of the pseudobulbs, which is time consuming with low proliferation and survival rates. The propagation by seed in the nature is hampered by the limited nutrients present in minute and dust-like seeds. With the advancement of tissue-culture technology, asymbiotic seed germination is now commonly used to ensure its propagation. Although there are reports on the asymbiotic seed germination of $S$. plicata using different medium formulations (Aswathi et al., 2017; Hossain and Dey, 2013; Minea et al., 2004; Thakur and Dongarwar, 2012), none of them examine in great depth the influence of culture media and incubation conditions on the speed of seed germination and seedling development. For commercial and amateur growers, as well as future breeders of $S$. plicata, a tissue-culture protocol that ensures rapid, uniform, and high rates of seed germination and seedling development is crucial. Hence, the present study was undertaken to examine the effect of different photoperiod and medium treatments on the speed of seed germination and seedling development in $S$. plicata.
Plant material. S. plicata plants were maintained in a greenhouse under natural light conditions, $70 \%$ relative humidity and $27 / 22{ }^{\circ} \mathrm{C}$ day/night temperature. When the flowers were fully opened, they were handpollinated by transferring pollinia onto the stigma of the same flower. Seed capsules were harvested $28 \mathrm{~d}$ after pollination.

Asymbiotic seed germination. The capsules were surface-sterilized using $70 \%$ ethanol for $1 \mathrm{~min}$ followed by $1 \% \mathrm{NaOCl}$ (with one drop of Tween-20) for $20 \mathrm{~min}$ under constant agitation. The capsules were rinsed three times with sterile distilled water to remove the chemical sterilant. The sterilized capsules were dissected longitudinally into two halves and seeds were collected from the capsules and sown on the surface of the culture medium $(\approx 100$ 200 seeds per petri dish). Five media were tested for seed germination and development, including the OSSM (P723; PhytoTechnology Laboratories, Lenexa, KS), BM-1 (B141; PhytoTechnology Laboratories), VW (V895; PhytoTechnology Laboratories), KC (K400; PhytoTechnology Laboratories), and 1/2 MS medium (Murashige and Skoog, 1962) (Table 1). The media were sterilized by autoclaving at $1.05 \mathrm{~kg} \cdot \mathrm{cm}^{-2}$ and $121^{\circ} \mathrm{C}$ for $15 \mathrm{~min}$ before being dispensed in 9 -cm petri dishes with 25 $\mathrm{mL}$ per dish. The petri dishes were sealed with double layers of parafilm before being incubated at $25{ }^{\circ} \mathrm{C}$ under $0 / 24$-h or $16 / 8 \mathrm{~h}$ light/dark photoperiods provided by cool fluorescent lights (Phillips F20T12/CW; Philips North American Corporation, Andover, MA) at $\approx 40 \pm 10 \mu \mathrm{mol} \cdot \mathrm{m}^{-2} \cdot \mathrm{s}^{-1}$. The influence of photoperiod and culture medium on seed germination was assessed over a period of 4 weeks. A germinated seed refers to a seed that has initiated germination (i.e., embryo swollen, Stage 1). The germination percentage was evaluated by dividing the number of germinated seeds by total number of seeds sown in each petri dish. Five replicate petri dishes were used for each medium treatment and the average was obtained from the five replicates.

Seedling development. Germinated seeds that proceeded through subsequent development stages are collectively termed seedlings in this study. Seedling development was scored on a scale of 0 to 6 (i.e., Stage 0: testa intact; Stage 1: embryo swollen; Stage 2: testa ruptured; Stage 3: appearance of protomeristem; Stage 4: emergence of first leaf; Stage 5: elongation of first leaf and its further development; Stage 6: emergence of second leaf) (Table 2). The influence of culture medium on the speed of seedling progression through six developmental stages under light conditions was evaluated with the aid of a dissecting microscope (Olympus SZ6045; Olympus, Tokyo, Japan) by determining the percentage of seedlings at each stage over a period of 16 weeks. The percentage of seedlings at a given development stage was evaluated by dividing the number of 


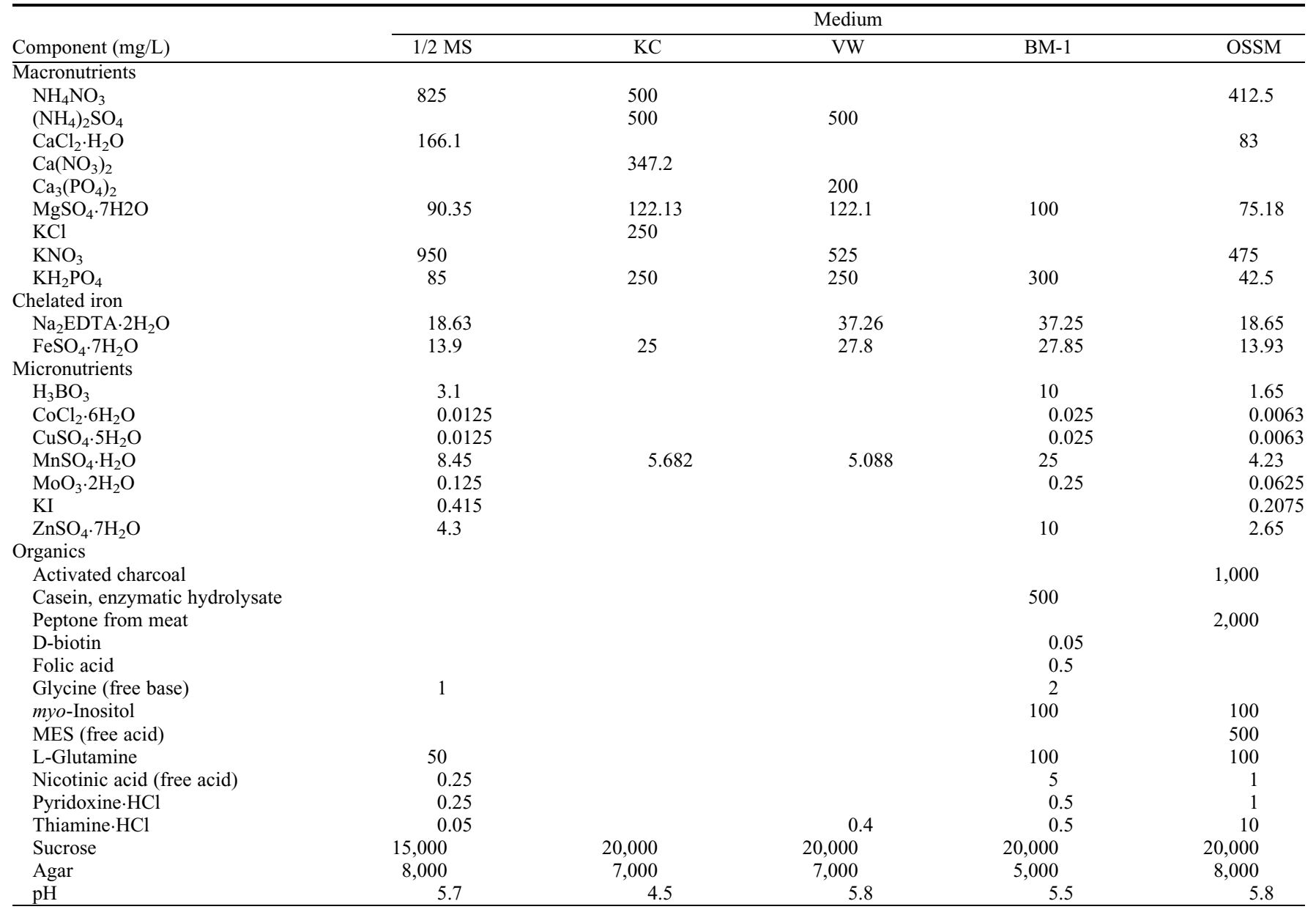

$1 / 2 \mathrm{MS}=$ half-strength Murashige and Skoog medium; KC = Knudson C Orchid Medium; VW = Vacin and Went Modified Orchid Medium; BM-1 = BM-1 Terrestrial Orchid Medium; OSSM = Orchid Seed Sowing Medium.

Table 2. Stages of seedling development in Spathoglottis plicata.

\begin{tabular}{ll}
\hline Stage & \multicolumn{1}{c}{ Description } \\
\hline 0 & Testa intact \\
1 & Embryo swollen \\
2 & Testa ruptured \\
3 & Appearance of protomeristem \\
4 & Emergence of first leaf \\
5 & Elongation of first leaf and its \\
& further development \\
6 & Emergence of second leaf \\
\hline
\end{tabular}

seedlings at that stage by the total number of germinated seeds or seedlings in each petri dish. Five replicate petri dishes were used for each medium treatment and the average was obtained from the five replicates.

Seedling acclimatization. Five-month-old seedlings with well-developed roots and shoots were selected and washed thoroughly under running tap water for 1 to $2 \mathrm{~min}$ to remove the adhering medium. Seedlings were transferred to 3-inch plastic pots containing $75 \mathrm{~g}$ of Stender peatmoss (KnownYou Seed Co., Ltd., Kaohsiung, Taiwan). The pots were kept inside a plastic tray inside the greenhouse. The tray was covered initially with a transparent polythene sheet to prevent desiccation during the early stage of acclimatization and the polythene sheet was gradually open every week until it was completely removed after 4 weeks. Irrigation started at the fifth week with a frequency of twice a week using tap water.

Data analysis. Complete randomized design was used for all the experiments. Data were analyzed using Waller-Duncan at $\alpha=$ 0.05 by SAS, version 9.00 (SAS Institute, 2002).

\section{Results}

Overview of seed germination, seedling development, and seedling acclimatization. An overview from seed germination to seedling acclimatization is presented in Fig. 1. The flowers (Fig. 1A) were self-pollinated and started to senesce $3 \mathrm{~d}$ after pollination. The seed capsules were cylindrical, green, and matured fast on this species (Fig. 1B). Green-pod sowing was started $28 \mathrm{~d}$ after pollination. Seeds incubated under $16 / 0-\mathrm{h}$ light/dark photoperiod became chlorophyllous and developed to Stage 1 (Fig. 1C) within 1 week of culture. Once the embryos reached Stage 1, they quickly progressed to the protocorm stage (Stage 2 ) with a loosened testa. Thereafter, the protocorms entered
Stage 3, which was characterized by completely detached testa, well-defined shoot apices (i.e., protomeristem), and/or outgrown rhizoids (Fig. 1D). Following the formation of the protomeristem, the protocorms reached Stage 4, where the leaf primordium was initiated. At the early seedling stage (Stage 5 ), the elongation of the first leaf was observed (Fig. 1E). Stage 6 was distinguished by having two expanded leaves (Fig. 1F). Seeds cultured under 0/24-h light/dark photoperiod also were capable of evolving through characteristic development stages, but seedlings reaching Stage 6 were achlorophyllous and etiolated (data not shown) and so were of inferior quality. Light-incubated seedlings were subcultured on the same medium until the acclimatization stage without the use of any plant growth regulator (Fig. 1G). All the seedlings survived acclimatization in the greenhouse using the peatmoss as the potting substrate (Fig. 1H).

Influence of photoperiod and culture medium on seed germination. The percentage of germinated seeds following different photoperiod and medium treatments over a 4week period is shown in Fig. 2. After 1 week of culture, seeds initiated germination on most of photoperiod and medium treatments except in the 1/2 MS-light and VW-light 

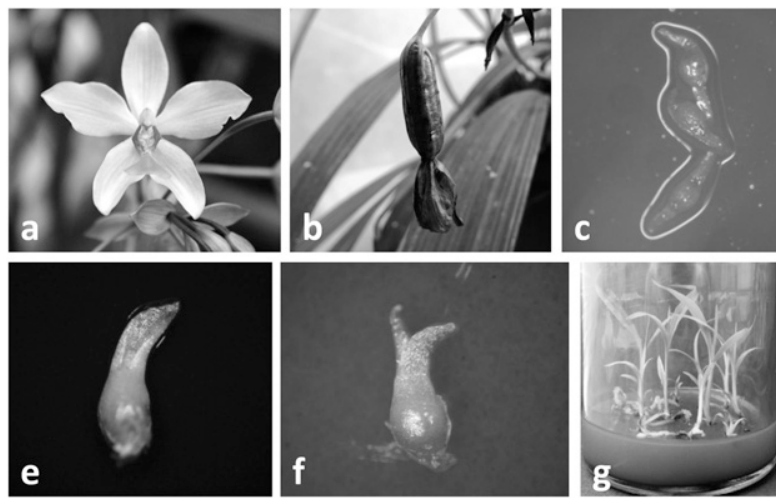

Fig. 1. Overview of asymbiotic seed germination, seedling development, and seedling acclimatization in Spathoglottis plicata. (A) S. plicata flower. (B) Immature seed capsule. (C) Stage 1 seedlings with swollen embryos. (D) Stage 3 seedling with distinguishable protomeristem. (E) Stage 5 seedling with elongated first leaf. (F) Stage 6 seedling with two expanded leaves. (G) Seedlings before acclimatization. (H) Seedlings after acclimatization.

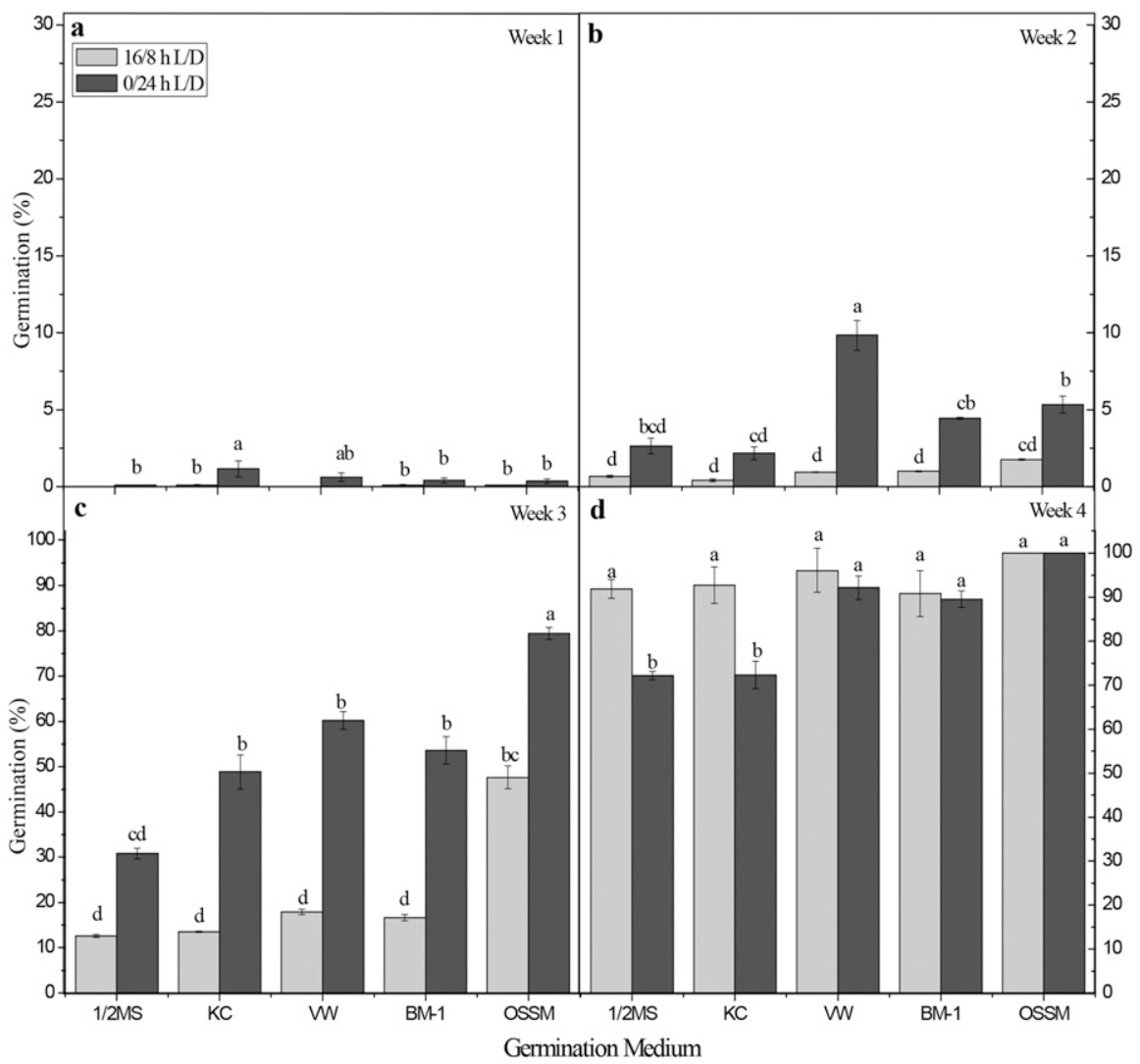

Fig. 2. Percentages of germinated seeds of Spathoglottis plicata under the influence of different photoperiod and medium treatments over a 4-week culture period. Means ( \pm SE) with the same letter are not significantly different $(\alpha=0.05)$.

treatments. After 2 weeks of culture, the percentage of germinated seeds incubated in the dark was greater compared with the light except for the $1 / 2 \mathrm{MS}$ and $\mathrm{KC}$ media, where no significant difference was found between light and dark treatments. The greatest percentage of germinated seeds was recorded with the VW medium (9.83\%). After 3 weeks of culture, all the media showed comparatively greater seed germination rates in the dark than in the light except for the $1 / 2$ MS medium, where no difference was found between light and dark. Among the dark treatments, the OSSM medium recorded the greatest rate of germinated seeds $(79.45 \%)$. After 4 weeks of culture, the percentage of germinated seeds incubated in the light was as high as or even superior to the percentage of germinated seeds incubated in the dark in all the media tested. Except for the KC and 1/2 MS dark treatments, which recorded only 72.17 and
$72.32 \%$ of germinated seeds, respectively, the remaining treatments showed more than $90 \%$ of germinated seeds, with the OSSM medium recording $100 \%$ of germinated seeds.

Influence of culture medium on seedling development. The percentage of seedlings present at different development stages on different media is presented in Fig. 3. In week 1 , only few seeds in the $\mathrm{KC}(0.09 \%), \mathrm{BM}-1$ $(0.10 \%)$, and OSSM $(0.08 \%)$ media progressed to Stage 1 of development. In week 2 , some seeds in the $1 / 2 \mathrm{MS}(0.66 \%)$ and VW $(0.95 \%)$ media also showed Stage 1 of development. In week 3 , seedlings in the OSSM medium showed the most rapid development, as some were found at Stages $2(9.91 \%), 3$ $(12.92 \%)$, and $4(2.77 \%)$ of development. A few seedlings in the $1 / 2 \mathrm{MS}(0.37 \%), \mathrm{KC}$ $(0.36 \%)$, and VW $(1.16 \%)$ media also evolved into Stage 3 of development, but at significantly lower rates than the OSSM medium. At week 4, all the Stage 0 seeds and Stage 1 seedlings in the OSSM medium evolved into Stages 3 and 4 of development. The greatest percentage of seedlings at Stage 4 was observed with the OSSM medium $(85.37 \%)$, followed by VW $(41.79 \%)$, KC (19.82\%), and 1/2 MS (14.71\%) media. None of the seedlings on the BM-1 medium showed Stage 4 of development. In week $5,49.40 \%$ and $0.61 \%$ of seedlings on the OSSM medium were in Stages 5 and 6 of development, respectively. A few seedlings on the VW medium $(0.25 \%)$ also advanced to Stage 5 , but the majority of the seedlings remained at Stages 3 and 4 . In week 6 , the percentages of seedlings on the OSSM medium at Stage 5 and Stage 6 increased to $60.98 \%$ and $31.55 \%$, respectively. In week 7 , no more seedlings were found at developmental stages 1 and 2 in all the media tested. Seedlings on the BM-1 medium showed the slowest development, with $43.5 \%$ of seedlings still remaining at Stage 3. Seedlings started to show Stages 5 and 6 of development on the $1 / 2 \mathrm{MS}, \mathrm{KC}$, and VW media. However, the greatest percentage of seedlings $(72.61 \%)$ at Stage 6 was still recorded with the OSSM medium. In week $8,35 \%$ of seedlings on the BM-1 medium were still found at Stage 3 of development, whereas those on the other media had all moved to more advanced stages. The OSSM medium contained the greatest percentage of Stage 6 seedlings $(84.40 \%)$, and this was followed by VW (66.05\%), KC (31.27\%), and 1/2 MS $(15.34 \%)$ media. In week 9 , the percentages of seedlings at Stage 6 of development were comparable between the OSSM $(89.33 \%)$ and VW $(80.51 \%)$ media. In week 10 , a few seedlings $(0.90 \%)$ on the BM-1 medium first entered Stage 5 of development. The greatest percentages of seedlings at Stage 6 were still recorded on the OSSM (97.67\%) and VW (97.82\%) media, respectively. In week 11 , all the seedlings on these two media reached Stage 6 of development. In week 12 , there was first appearance of seedlings at Stage 6 on 

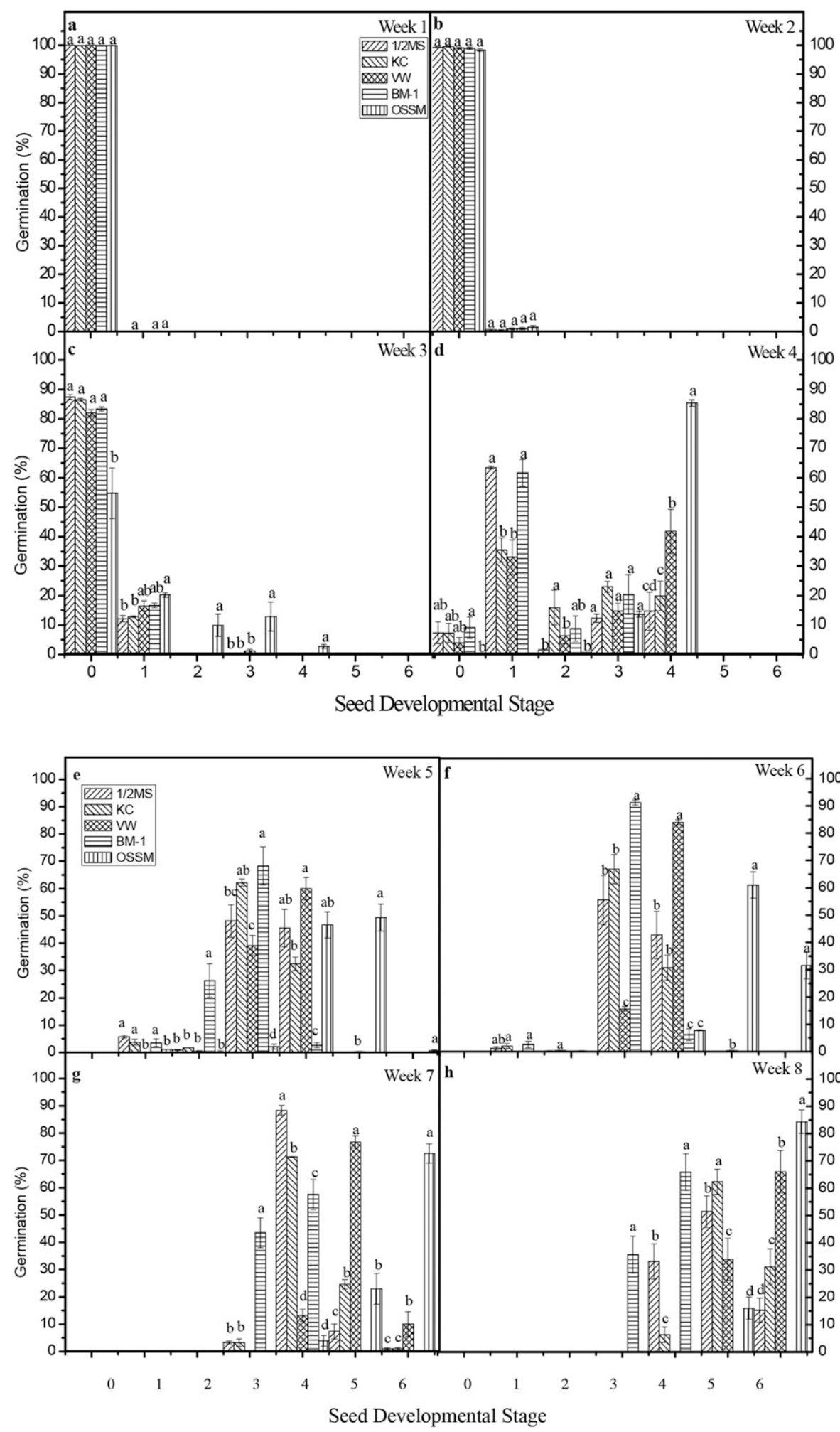

Fig. 3. Percentages of Spathoglottis plicata seedlings at different development stages on different media under light condition over a 16-week culture period. Means $( \pm \mathrm{SE})$ within each development stage with the same letter are not significantly different $(\alpha=0.05)$.

the BM-1 medium. All the seedlings from the $1 / 2 \mathrm{MS}$ and $\mathrm{KC}$ media progressed to Stage 6 in week 13. Seedlings on the BM-1 medium continued their development in weeks 14 and 15 , and eventually, 98.93\% of them reached Stage 6 of development in week 16.

\section{Discussion}

The influence of light and darkness on seed germination often is overlooked and not well understood for terrestrial orchid species and has not been examined before for $S$. plicata. Complete darkness often is consid- ered to promote germination of terrestrial orchids. Seed germination in many temperate terrestrial orchids often is inhibited by light incubation (Arditti et al., 1981; Ernst, 1982; Van Waes and Debergh, 1986). Many terrestrial orchids grow in more shaded environments than their epiphytic counterparts, and light may not reach the habitat floor as readily. Upon dehiscence, seeds of terrestrial orchids may not germinate until they are buried. S. plicata may have improved germination in complete darkness, possibly due to its terrestrial background. The negative impact of light in terrestrial orchid seed germination also was recorded by Arditti et al. (1981), where light decreased germination of Calypso bulbosa and Epicactis gigantean seeds. Results in this study have further demonstrated the importance of light in seedling development of $S$. plicata. Comparative results were found with Calopogon tuberosus, where seeds at an advanced stage (Stage 6) were only observed under light incubation (Kauth et al., 2006). Similarly, although light was not a limiting factor for early stages of seed germination, it was essential for subsequent seedling development in Dendrobium aqueum (Parthibhan et al., 2012). The authors observed that the 0/24-h light/dark photoperiod supported seeds up to the protocorm stage with poor seedling growth; seedling development occurred only when longer photoperiods were used. Nevertheless, results in our study indicate that $S$. plicata seeds incubated in the dark were capable of reaching the advanced seedling stage, as opposed to the findings of Kauth et al. (2006) and Parthibhan et al. (2012), where seedling growth was arrested in the absence of light. This may suggest the lower light requirement for seedling development of $S$. plicata compared with the other two orchid species.

Successful in vitro seed germination has been reported for $S$. plicata using various medium formulations. Hossain and Dey (2013) found that the maximum seed germination percentage was observed with the Phytamax medium (95\%) followed by the OSSM medium (90\%) after 5 weeks of culture. Thakur and Dongarwar (2012) obtained $87.3 \%$ germination and complete seedling development (reaching Stage 6) within 11 weeks when the seeds were cultured on $1 / 2$ MS medium. Kheawwongjun and Thammasiri (2008) obtained near 100\% germination using the modified semisolid VW medium. Minea et al. (2004) reported greater than $65 \%$ seed germination after 3 to 4 weeks on semisolid or liquid Knudson C medium. Aswathi et al. (2017) reported germination rates of $95 \%, 90 \%$, and $25 \%$ using B5, KC, and MS media, respectively. In the present study, where we compared the efficiency of seed germination and seedling development between five different culture media, it was observed that all the $S$. plicata seeds were capable of germinating and reaching the Stage 6 of development no matter which medium was used if they were given sufficient time. However, the speed of 

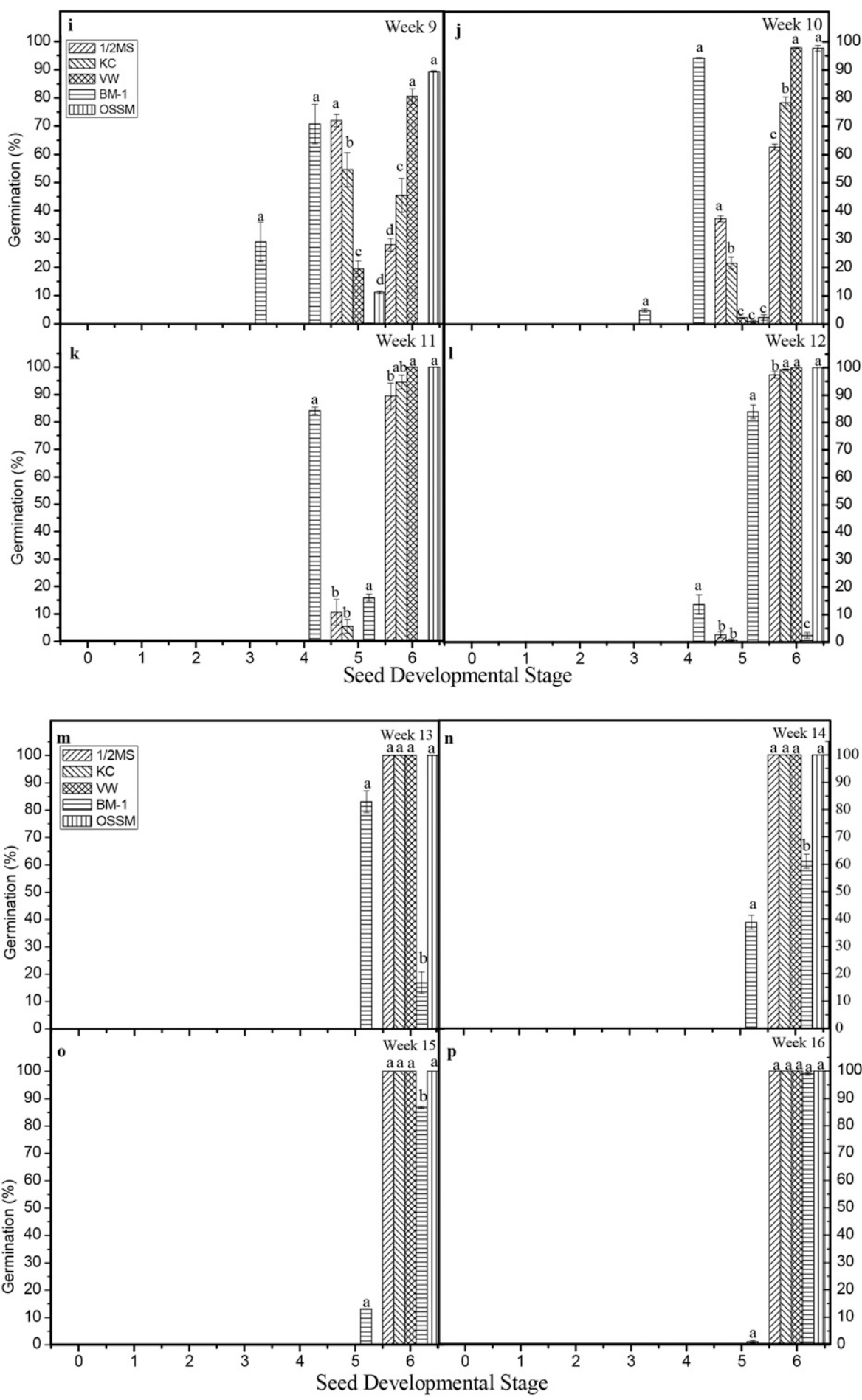

Fig. 3. (Continued)

seedling development depended largely on the medium used. Seedlings on the OSSM and VW media evolved the fastest as they reached Stage 6 of development in 11 weeks' time, followed by the seedlings on the KC and $1 / 2$ MS media, which required 13 weeks; seedlings on the BM-1 medium evolved the slowest and required more than 16 weeks' time to complete seedling development.

The medium composition is one of the most important factors governing the success of micropropagation. Among the medium components, nitrogen often has been regarded as one of the key ingredients. The vitro growth and development of Habenaria macroceratitis seeds. In this study, the slowest seed germination and seedling development was observed with the BM-1 medium. The BM-1 medium contained only organic nitrogen source in the form of amino acids, namely glycine and glutamine. Although Malmgren (1996) suggested that an organic nitrogen source provided in the form of an amino acid might be more readily available due to simplified forms of nitrogen, glycine, the simplest amino acid, has been found to decrease germination of Cattleya seeds from $53 \%$ to $41 \%$ (Raghavan, 1964). Curtis and Spoerl (1948) also demonstrated that glycine significantly reduced germination of Cattleya seeds. Raghavan (1964) found that only certain amino acids were as effective as ammonium in germinating Cattleya seeds. Seed germination in the presence of other amino acids (i.e., arginine, proline, glutamine, etc.) was comparable with germination with ammonium nitrate. On the opposite end, the OSSM medium, which showed the fastest seedling development in this study, contained both organic and inorganic nitrogen. Besides amino acids, the medium also contained peptone. The beneficial effect of peptone on asymbiotic seed germination of orchids also has been reported previously. Curtis (1947) reported that the seed germination percentages of Paphiopedilum insigne and Paphiopedilum hirsutissimum were $30 \%$ greater with $2 \mathrm{~g} / \mathrm{L}$ peptone than without peptone. In a more recent study, Hossain and Dey (2013) found that the maximum germination of mature seeds of $S$. plicata (i.e., 95\% and 90\%) was recorded in Phytamax and OSSM media, respectively, which both contained 2 $\mathrm{g} / \mathrm{L}$ peptone. It also should be noted that in this study, the fact that the VW medium showed comparable performance with the OSSM medium (seedlings reaching Stage 6 of development in 11 weeks' time) may suggest that the presence of inorganic nitrogen alone in the medium was sufficient for seed germination and seedling development in S. plicata. The other two media used in this study, namely $1 / 2 \mathrm{MS}$ and $\mathrm{KC}$, contained also inorganic nitrogen as the nitrogen source, but in both the nitrate and ammonium forms. Since they allowed slower seedling development than the VW medium, this may imply that although ammonium was beneficial for $S$. plicata seed germination and seedling development, the presence of nitrate together with ammonium in the medium was unfavorable. Our finding is in agreement with Curtis (1947) and Raghavan and Torrey (1964), where the seeds of a Cattleya hybrid germinated more efficiently on media containing an ammonium source rather than a nitrate or nitrite source. Several researchers reported that inorganic nitrogen in the form of nitrate may limit germination, possibly due to low nitrate reductase activity during seed germination and early protocorm development (Malmgren, 1996; Raghavan and Torrey, 1964; Van Waes and Debergh, 1986).

Phosphate availability in the culture medium also may affect seed germination in $S$. 
plicata. The VW medium contained a greater phosphate concentration $(3.77 \mathrm{~mm})$ than all the other media tested (i.e., $1.84 \mathrm{~mm}$ in $\mathrm{KC}$, $0.31 \mathrm{~mm}$ in OSSM, $0.63 \mathrm{~mm}$ in $1 / 2 \mathrm{MS}$, and $2.20 \mathrm{~mm}$ in BM-1). The VW medium supported a high number $(100 \%)$ of advancedstage seedlings (Stage 6) within 11 weeks of culture, and this may be due to a greater phosphate concentration available to developing seeds of S. plicata. Dutra et al. (2008) observed the same pattern with the VW medium, which supported a high number $(35.5 \%)$ of advanced-stage seedlings (Stage 6) of Bletia purpurea, whereas the KC, 1/2 MS, and BM-1 media only supported high numbers of Stages 4 and 5 seedlings. Dijk and Eck (1995) studied the effects of phosphate concentration on seedling growth of Dactylorhiza majalis, and their results showed that those cultured in the presence of high concentrations of phosphate $(10 \mathrm{~mm})$ had a greater fresh weight than the control treatment (1 mM).

Molybdenum is an important element that should be included in any plant culture medium (Gamborg et al., 1976). Although required in small quantities, molybdenum is essential for nitrogen assimilation, biosynthesis of abscisic acid, purine catabolism, and sulfur reduction (Mendel and Hänsch, 2002). Breddy (1953) found that the addition of molybdenum in combination with other micronutrients to the culture media increased both seed germination and seedling growth of orchids. In contrast, greater ammonium nitrate concentrations significantly decreased the concentration of molybdenum in leaf tissue of eggplant (Víllora et al., 2002). The reduced molybdenum concentration was responsible for a decrease in the capacity of the plant to reduce nitrate to ammonium and ammonium to amino acids (Kauth et al., 2006). The OSSM medium in this study may have enhanced germination, growth, and development of $S$. plicata seeds due to the presence of molybdenum in the medium. Kauth et al. (2006) also found that Calopongon tuberosus seeds germinated better and developed faster to Stage 6 seedlings on the OSSM medium.

Niacin has been found to be beneficial for orchid seed germination (Arditti, 1967). The OSSM medium contained nicotinic acid, a derivative of niacin, which is essential for metabolism of components $\mathrm{NAD}^{+}$and $\mathrm{NADP}^{+}$(Kauth, 2005). Consequently, metabolism may be more efficient in seeds of $S$. plicata cultured on the OSSM medium than on other media assessed. Effectiveness of niacin also was reported by Kauth et al. (2006), where increased growth and vigor were observed in seeds of Calopogon tuberosus.

In conclusion, the photoperiod and culture medium were two important factors governing the speed of seed germination and seedling development in $S$. plicata. The fastest and complete seed germination and seedling development was obtained with the OSSM and VW media under 16/8-h light/dark photoperiod incubation.

\section{Literature Cited}

Anderson, A.B. 1996. The reintroduction of Platanthera ciliaris in Canada, p. 73-76. In: C. Allen (ed.). North American native terrestrial orchids propagation and production. North American Terrestrial Orchid Conference, Germantown, MD.

Arditti, J. 1967. Factors affecting the germination of orchid seeds. Bot. Rev. 33:1-97.

Arditti, J., J.D. Michaud, and A.P. Oliva. 1981 Seed germination of North American orchids. I. Native California and related species of $\mathrm{Ca}$ lypso, Epipactis, Goodyera, Piperia, and Platanthera. Bot. Gaz. 142:442-453.

Aswathi, S. Shibu, A. Gopinath, and A. Mohan. 2017. In vitro propagation of Spathoglottis plicata Blume via asymbiotic seed germination. Intl. J. Adv. Res. 5(3):431-438.

Beltrame, E. 2006. Spathoglottis-Inside and out. Orchid Rev. 114:68-71.

Breddy, N.C. 1953. Observations on the raising of orchids by asymbiotic cultures. Amer. Orchid Soc. Bull. 22:12-17.

Chen, S.C. and A. Bell. 2009. Spathoglottis Blume, Bijdr. 400. 1825. Flora China 25:287-288.

Curtis, J.T. 1947. Studies on the nitrogen nutrition of orchid embryos. I. Complex nitrogen sources. Amer. Orchid Soc. Bull. 16:654-660.

Curtis, J.T. and E. Spoerl. 1948. Studies on the nitrogen nutrition of orchid embryos II. Comparative utilization of nitrate and ammonium nitrogen. Amer. Orchid Soc. Bull. 17:111-114.

Dijk, E. and N. Eck. 1995. Anexic in vitro nitrogen and phosphorus responses of some Dutch marsh orchids. New Phytol. 131:353-359.

Dutra, D., T.R. Johnson, P.J. Kauth, S.L. Stewart, M.E. Kane, and L. Richardson. 2008. Asymbiotic seed germination, in vitro seedling development, and greenhouse acclimatization of the threatened terrestrial orchid Bletia purpurea. Plant Cell Tissue Organ Cult. 94:11-21.

Ernst, R. 1982. Orchid seed germination and seedling culture-A manual: Paphiopedilum, p. 350-353. In: J. Arditti (ed.). Orchid biologyreviews and perspectives II. Cornell University Press, Ithaca, NY.

Gamborg, O.L., T. Murashige, T.A. Thorpe, and I.K. Vasil. 1976. Plant tissue culture media. In Vitro 12:473-478.
Hossain, M.M. and R. Dey. 2013. Multiple regeneration pathways in Spathoglottis plicata BlumeA study in vitro. S. Afr. J. Bot. 85:56-62.

Kauth, P.J. 2005. In vitro seed germination and seedling development of Calopogon tuberosus and Sacoila lanceolata var. lanceolata: Two Florida native terrestrial orchids. University of Florida, master's thesis.

Kauth, P.J., W.A. Vendrame, and M.E. Kane. 2006. In vitro seed culture and seedling development of Calopogon tuberosus. Plant Cell Tissue Organ Cult. 85:91-102.

Kheawwongjun, J. and K. Thammasiri. 2008. Breeding Spathoglottis spp. for commercial potted orchids. Acta Hort. 788:47-52.

Malmgren, S. 1996. Orchid Propagation: Theory and Practice, p. 63-71. In: C. Allen (ed.). North American native terrestrial orchids propagation and production. North American Terrestrial Orchid Conference, Germantown, MD.

Mendel, R.R. and R. Hänsch. 2002. Molybdoenzymes and molybdenum cofactor in plants. J. Expt. Bot. 53:1689-1698.

Minea, M., C. Piluek, A. Menakanit, and S. Tantiwiwat. 2004. A study on seed germination and seedling development of Spathoglottis B1. orchids. Kasetsart J. Nat. Sci. 38:141-156.

Murashige, T. and F. Skoog. 1962. A revised medium for rapid growth and bioassays with tobacco tissue cultures. J. Plant Physiol. 122: 211-215.

Parthibhan, S., J.H. Franklin Benjamin, M. Muthukumar, N. Ahamed Sherif, T. Senthil Kumar, and M.V. Rao. 2012. Influence of nutritional media and photoperiods on in vitro asymbiotic seed germination and seedling development of Dendrobium aqueum Lindley. Afr. J. Plant Sci. 6:383-393.

Raghavan, V. 1964. Effects of certain organic nitrogen compounds on growth of in vitro seedling of Cattleya. Bot. Gaz. 125:260 267.

Raghavan, V. and J.G. Torrey. 1964. Inorganic nitrogen nutrition of the seedling of the orchid, Cattleya. Amer. J. Bot. 51:264-274.

SAS Institute Inc. 2002. SAS Version 8.2. SAS Institute, Cary, NC.

Stewart, S.L. and M.E. Kane. 2006. Asymbiotic seed germination and in vitro seedling development of Habenaria macroceratitis (Orchidaceae), a rare Florida terrestrial orchid. Plant Cell Tissue Organ Cult. 86:147158.

Thakur, U. and N. Dongarwar. 2012. Artificial pollination and in vitro asymbiotic seed germination in garden orchid Spathoglottis plicata Blume (Orchidaceae). Recent Res. Sci. Technol. 4:13-18.

Van Waes, J.C. and P.C. Debergh. 1986. In vitro germination of some western European orchids. Physiol. Plant. 67:253-261.

Víllora, G., D.A. Moreno, and L. Romero. 2002. Response of eggplant to nitrogen supply: Molybdenum-nitrate relationships. Biol. Plant. 45:621-623. 